\title{
Toxoplasma gondii Infection Delays the Onset and Decreases the Severity of Rheumatoid Arthritis in a Programmed Death-1 Mediated Mechanism
}

\author{
Shaimaa Ahmed Sharaf El-Deen ${ }^{1 *}$, Reham Mustafa Brakat ${ }^{1,2}$, \\ Reem Mohsen EL-Kholy ${ }^{3}$, Dalia Salah Saif ${ }^{4}$ and Shaimaa Sherif Soliman ${ }^{5}$ \\ ${ }^{1}$ Parasitology Department, ${ }^{3}$ Clinical Pathology Department, ${ }^{4}$ Physical Medicine, \\ Rheumatology and Rehabilitation Department, ${ }^{5}$ Public Health and Community Medicine, \\ Faculty of Medicine, Menoufia University, Egypt \\ ${ }^{2}$ Biomedical Science Department, College of Medicine, King Faisal University, Al Ahsa, KSA \\ *Corresponding author
}

\section{A B S T R A C T}

\section{Keywords}

Rheumatoid arthritis,

Toxoplasmosis, Programmed death-1, Immunomodulation

Article Info

Accepted:

04 April 2019

Available Online:

10 May 2019
Rheumatoid arthritis (RA) is a common autoimmune disorder that affects around $1 \%$ of the world's population. The associating morbidity extends out of the joints to involve many vital organs in addition to increased mortality rates. Environmental infections are one of the accused elements to be a risk factor for RA. The relationship between RA and toxoplasmosis was a point of controversy where most of the human studies reported either absent or positive correlation. They usually linked toxoplasmosis to suppressed immunity by the drugs used for RA treatment which enhances activation of latent infections. The current work studied the actual effect of toxoplasmosis on RA by excluding the immunesuppressive action of drugs. The studied population was all newly diagnosed cases who did not start RA treatment. We also studied the effect of programmed death-1, PD-1 (which is overexpressed in chronic toxoplasmosis) on RA severity. We recorded a higher age of onset and decreased severity markers of RA in toxoplasmosis positive patients. The higher lymphocytic PD-1 expression that associated toxoplasmosis was negatively correlated to RA severity. We concluded that toxoplasmosis delayed onset of RA and decreased its severity. These effects can be related to the toxoplasmosis associated increase in lymphocytic PD-1 expression.

\section{Introduction}

Rheumatoid arthritis (RA) is a chronic autoimmune disorder that results in progressive articular destruction and many comorbidities in vascular, metabolic, bone and psychological domains (McInnes and Schett, 2017). It affects $0.3-1 \%$ of the population allover the world. $0.8 \%$ of all disability-adjusted life years lost in Europe is caused by RA. According to the World Health Organization (WHO), 50\% of RA patients can't continue their work within 10 years of disease onset. In addition to depression which is a common sequel of the associating pain, disability, and increased health care 
expenditures. The associating increased mortality rate is usually related to cardiovascular problems that complicates RA (Englbrecht et al., 2013; Gulácsi et al., 2015; Taylor et al., 2016; Deb et al., 2018).

Genetic architecture of RA patients revealed that most of the 100 loci responsible for disease susceptibility or progression implicate immune effector or regulatory gene products (McInnes and Schett, 2017). That's why blocking the proinflammatory or enhancing the immune-regulatory mediators are the main targets for drug research to overcome the unresponsiveness of some patients to the traditional disease-modifying agents. One of the important molecules that suppress the immune response and is usually deficient, mutated or malfunctioning in RA patients is programmed death-1 (PD-1). This molecule is expressed on a wide variety of immune cells. Once activated, it inhibits both $\mathrm{T}$ cell and B cell activation cascade. It was also proved to directly affect RA severity. Moreover, RA susceptibility is affected by PD-1 polymorphisms (Prokunina et al., 2004; Raptopoulou et al., 2010; Liu et al., 2014; Sandigursky et al., 2017). These findings highlight the potential importance of devising future therapies that can modulate lymphocyte activation through targeting of the PD1/programmed death ligands (PD-Ls) pathways. This immune-modulating element, PD-1 is also expressed on lymphocytes in chronic infections and is responsible for reactivation of latent infections of the protozoan parasite, T. gondii (Bhadra et al., 2011, 2012; Moretto et al., 2017; Xiao et al., 2018).

T. gondii is an obligatory intracellular parasite that can infect any vertebrate animal and remains in his tissues for-life. Its infections usually pass unnoticed in immunocompetent hosts and can be reactivated if host immunity is suppressed (Halonen and Weiss, 2013). The relationship between RA and toxoplasmosis is a point of controversy (Hosseininejad et al., 2018). Some experimental studies reported a negative correlation (Washino et al., 2012) while many human studies reported the reverse where $T$. gondii immunoglobulins (Ig) were detected in sera of RA patients more than healthy controls. These studies usually explained this link by the fact that patients who develop autoimmune diseases have disturbed immune responses that facilitate reactivation of latent infections. Others regarded it to the usage of immunesuppressive drugs that renders the patients more susceptible to opportunistic infections. Other studies supported both points of view and suggested a reciprocal relationship theory (Listing et al., 2013; El-Henawy et al., 2017; Tian et al., 2017). The sharing point among these studies is that all of them were held on patients who are already on treatment that may be the cause of $T$. gondii infection or at least reactivation of latent infections. Previously we reported on the PD-1-mediated protective effect of $T$. gondii antigens against experimental autoimmune encephalomyelitis - the animal model of multiple sclerosis (Sharaf EL-Deen et al., 2018). In the present study, we investigated its role in RA. Unlike the previous similar studies, our studied population was recently diagnosed RA patients who didn't start RA therapy nor received any immune-suppressive drugs that may increase the risk of $T$. gondii infection. The present work also studied the possible influence of $T$. gondii-induced PD-1 on the severity of RA.

\section{Materials and Methods}

\section{Ethical considerations}

This study was approved by the Research Ethics Committee of Faculty of Medicine, Menoufia University, Egypt. The aim of the study was explained to all participants and 
informed consents were obtained from all of them.

\section{Subjects and study design}

This study was a case-control study. It was performed on 100 RA patients attending the outpatient clinic of Physical Medicine, Rheumatology and Rehabilitation Department at Menoufia University Hospitals, Menoufia, Egypt. Duration of the study extended from January 2017 to Mars 2019. All patients underwent full history taking, clinical examination and they were classified according to the classification criteria of the American College of Rheumatology/ European League against Rheumatism (Aletaha et al., 2010). Inclusion criteria were, recently diagnosed RA patients and didn't start treatment. Exclusion criteria were other types of arthritis, encountering immunesuppressive diseases or receiving any immune-suppressive drugs. A control group of 50 healthy non-rheumatoid individuals [negative rheumatoid factor (RF) and anticyclic citrullinated peptide antibodies (ACCPA)] and with matched age and sex was included.

Patients were divided into two groups. GI: non-rheumatoid healthy controls (HC). GII: RA patients. Each group was further subdivided into two subgroups, GIa: RA and T. gondii negative $\left(\mathrm{HC} / \mathrm{T}^{--}\right)$. GIb: RA negative and $T$. gondii positive $\left(\mathrm{HC} / \mathrm{T}^{+}\right)$. GIIa: RA positive and $T$. gondii negative $\left(\mathrm{RA} / \mathrm{T}^{--}\right)$. GIIb: RA and $T$. gondii positive $\left(\mathrm{RA} / \mathrm{T}^{+}\right)$.

\section{Diagnosis of RA and assessment of degree disease of severity}

Peripheral blood samples were collected from patients and controls. Laboratory tests included erythrocyte sedimentation rate (ESR) by Westergren method (Gilmour and Sykes, 1951), C-reactive protein (CRP), RF using nephelometric technology on MISPA-i2 analyzer (Agappe Diagnostics Ltd., Kerala, India); and ACAPA using electrochemiluminescence on Cobas e411 immunoassay analyzer (Roche Diagnostics, Mannheim, Germany). Steps of tests were performed according to manufacturers' protocols.

Disease activity score 28 , DAS28 index was calculated after the examination of 28 swollen and tender joints involving hands, arms and knees and linking results of their examination in a mathematical formula with results of ESR and CRP. The DAS28 ranges from 1 to 9 where a low score $(<3.2)$ indicates a low disease activity, a moderate score (3.2-5.1) indicates moderate disease activity and a high score (> 5.1) indicates high disease activity (Anderson et al., 2011).

\section{Assessment of $T$. gondii positivity}

Serum samples of all participants were analyzed for anti- T. gondii IgG antibodies using commercial enzyme immunoassay, Human Anti-T. gondii IgG kit (ab108776, Abcam, USA) in accordance with manufacturer's recommendations. Positive samples were analyzed for anti- T. gondii IgM antibodies using Human Anti-T. gondii IgM Kit (ab108778, Abcam, USA) to exclude acute infection. Anti- T. gondii IgG and IgM antibody levels were expressed as $\mathrm{U} / \mathrm{ml}$.

\section{Assessment of PD-1 expression on $\mathrm{CD}^{+}$ lymphocytes by flow cytometry}

$25 \mu 1$ of EDTA-anti-coagulated blood was mixed thoroughly with $2 \mu \mathrm{l}$ of the following mouse anti-human monoclonal antibodies, CD279 (PD-1) phycoerythrin, PE (lot 5181224067, MiltenyiBiotec, USA) and CD4 fluorescein isothiocyanate, FITC (BD 7156809, Biosciences, USA). Blood samples were incubated for $20 \mathrm{~min}$. at room 
temperature in the dark. Red blood cells were lysed by adding $1 \mathrm{ml}$ of lysing solution for 5 min. Then, samples were washed twice using phosphate buffered saline (PBS) and finally, the cells were suspended in $200 \mu$ of PBS for flow cytometric analysis.

PD $-1^{+} \mathrm{CD} 4^{+}$cell percentage was determined by analysis on FACS Calibur (Becton Dickinson Immunocytometry Systems, San Jose, CA, USA), gating was done on lymphocytes using side versus forward scatter and at least 10,000 events were acquired.

\section{Statistical analysis}

SPSS was used for data analysis (SPSS Inc. Released in 2015. IBM SPSS statistics for windows, version 23.0, Armonk, NY: IBM Corp). The Normality of the data was tested by Kolomogrov and Shapero tests. Chi-square test $(\chi 2)$ was used to study the association between qualitative variables and whenever any of the expected cells were less than five, Fischer's Exact test was used. Data of the quantitative type were expressed in Mean and Standard Deviation. Mann Whitney's test was used for comparison of quantitative variables between two groups. Spearman correlation was used to express the correlation between different variables. Kruskal Wallis test was used for comparison of quantitative variables between more than two groups of not normal distributed data with Tamhane's test as a post hoc test. The level of significance of the present data was $95 \%$, so, p-value $>0.05$ was considered as non-statistically significant difference, while p-value $<0.05$ was considered as statistically significant difference.

\section{Results and Discussion}

\section{Prevalence of toxoplasmosis is not different between RA patients and $\mathrm{HC}$}

Insignificant difference was detected between both groups regarding positivity for toxoplasmosis [Figure 1a]. Opposing results were obtained by Shapira et al., (2012); ElSayed et al., (2016); El-Henawy et al., (2017); and Tian et al., (2017) who recorded higher prevalence of toxoplasmosis among RA patients compared non-RA individuals. Unlike our work, their studies were held at least 6 months after onset of treatment which by itself is a risk factor for encountering infections due to the associating immunesuppression (Young and McGwire, 2005; Lassoued et al., 2007; El-Sayed et al., 2015). Actually, they assessed the effect of RA on $T$. gondii not the reverse. Some of these authors related the higher incidence of RA in $T$. gondii positive patients to the geographical distribution of patients who share genetic susceptibility to autoimmune diseases and lifestyles that facilitates infection (Shapira et al., 2012; Tian et al., 2017).

Despite the absence of the significant difference between $\mathrm{HC}$ and RA groups regarding $T$. gondii $\mathrm{IgG}$ positivity, mean IgG titer was significantly higher in RA than the HC group with negative IgM in both groups [Figure 1b]. This finding may reflect reactivation of latent infection. Activation of infection is a common sequela of RA due to the associating premature aging of the immune system with increased apoptosis and/or malfunction of innate and adaptive immune cells. Moreover, the immunesuppressing drugs enhance this reactivation in a dose-dependent manner (listing et al., 2013). Similarly, El-Sayed et al., (2016) and El-Henawy et al., (2017) reported a statistically significant higher anti-T. gondii antibody titers in RA patients than control non-RA individuals.

\section{$\mathrm{RA} / \mathrm{T}^{+}$patients have delayed disease onset}

A statistically significant difference was detected between the mean ages of both RA subgroups where $\mathrm{RA} / \mathrm{T}^{+}$patients had a higher mean age of onset than RA/T ones [Figure 
1c]. This can be related to the statistically significant increase of the immunesuppressing molecule PD-1 that occurred in $\mathrm{RA} / \mathrm{T}^{+}$patients and correlated negatively with the age of RA onset.

Similarly, Washino et al., (2012) recorded a delay in the onset of spontaneous arthritis (an animal model of RA) in $T$. gondii infected IL1Ra-deficient mice than non-infected ones. They related this delay to the immunedownregulation that associated $T$. gondii infection at both cellular and transcriptional levels. Also, the human study held by Fischer et al., (2013) reported that RA appeared at an older age in chronic toxoplasmosis patients.

Delayed onset of RA manifestations is supported by findings of our previous work on the experimental model of the autoimmune disease, multiple sclerosis. Immunization of mice with soluble antigens of $T$. gondii tachyzoites was associated with a PD-1dependent suppression of the proinflammatory cytokines, IL-17, and INF- $\mathrm{X}$ with a subsequent delay in the appearance of the clinical manifestations of the disease (Sharaf El-Deen et al., 2018).

\section{$\mathrm{RA} / \mathrm{T}^{+}$patients have decreased disease activity scores and severity markers}

All laboratory investigations for disease severity - and subsequently prognosis - (i.e. RF, ACAPA, ESR, and CRP) and DAS28 scores were lower in $\mathrm{RA} / \mathrm{T}^{+}$patients than $\mathrm{RA} / \mathrm{T}$ ones. Differences were statistically significant in comparison of all assessed parameters.

This can be related to the statistically significant increase of the immunesuppressive PD-1 expression on $\mathrm{CD}^{+}$ lymphocytes which correlated negatively with all assessed parameters of severity [Figures 1d-1h]. Similarly, Washino et al., (2012) postulated an immune modulating action of $T$. gondii which could decrease disease severity in RA-animal model through suppression of the proinflammatory cells, Th17.

The contradicting results of El-Sayed et al., (2016) and El-Henawy et al., (2017) who reported a positive correlation between latent toxoplasmosis and severity of RA manifestations can be explained by the higher degree of immune dysregulation - that appeared clinically as higher activity scores even with the use of drugs-. The higher the RA severity, the more the risk of acquiring $T$. gondii infection or at least activation of latent infections (Doran et al., 2002).

\section{RA/ $\mathbf{T}^{+}$patients have a higher lymphocytic expression of PD-1}

Because RA is more T helper cell-controlled, we focused on PD-1 expression on $\mathrm{CD}^{+}$ lymphocytes. We found that percentage of $\mathrm{CD} 4^{+}$lymphocytes that expressed PD-1 was statistically higher in $\mathrm{RA} / \mathrm{T}^{+}$patients than $\mathrm{RA} / \mathrm{T}$ ones. Moreover, this percent correlated negatively with all scores of disease severity [Figure 2]. These findings are supported by Ceeraz et al., (2013) and Li et al., (2014). They reported decreased PD-1 expression on both $\mathrm{CD}^{+}$and $\mathrm{CD}^{+}$ lymphocytes of RA patients. They correlated degree of disease severity scores to the degree of reduction of lymphocytic PD-1 expression because PD-1 and its ligands are responsible for downregulation of the effector lymphocytes - with subsequent immune suppression - through induction of lymphocytic apoptosis.

Greisen et al., (2017) reported similar results. They even reported a failure of upregulation of the miRNAs of synovial fluid mononuclear cells, PD-1 upon stimulation. 
Fig.1 Comparison between the studied groups regarding a. Prevalence of toxoplasmosis in HC and RA patients; b. Serum levels of T. gondii IgG in HC and RA patients; c. Mean age of disease onset in RA/T and RA/T $\mathrm{T}^{+}$patients; $\mathbf{d}$. ESR of RA/T and RA/T ${ }^{+}$patients; e. CRP of RA/T and $\mathrm{RA} / \mathrm{T}^{+}$patients; $\mathbf{f}$. ACAPA of RA/T ${ }^{-}$and RA/T $\mathrm{T}^{+}$patients; $\mathbf{g}$. $\mathrm{RF}$ of RA/T and $\mathrm{RA} / \mathrm{T}^{+}$ patients; h. DAS28 of RA/T and RA/T $\mathrm{T}^{+}$patients

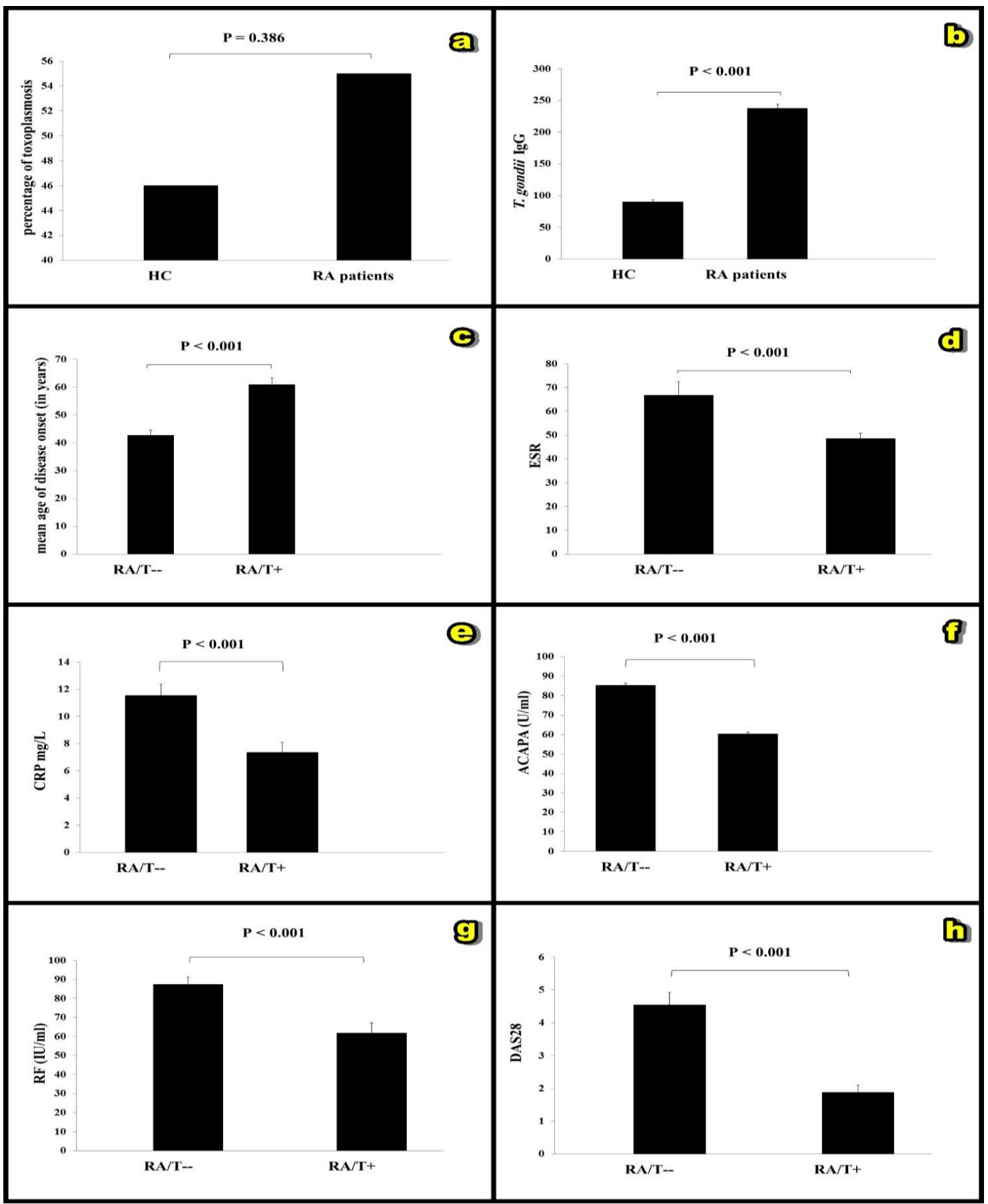


Fig.2 a. Comparison of $\mathrm{CD}^{+}$lymphocytic PD-1 expression among the studied groups. b. Flowcytometric data of $\mathrm{CD}^{+}{ }^{+}$lymphocytes' $\mathrm{PD}-1$ expression in $\mathrm{RA} / \mathrm{T}^{-}$patients. c. Flowcytometric data of $\mathrm{CD}^{+}{ }^{+}$lymphocytes' $\mathrm{PD}-1$ expression in $\mathrm{RA} / \mathrm{T}^{+}$patients.

d. Correlation between $\mathrm{CD}^{+}{ }^{+}$lymphocytes' PD-1 expression and ESR.

e. Correlation between $\mathrm{CD} 4^{+}$lymphocytes' PD- 1 expression and CRP level.

f. Correlation between $\mathrm{CD}^{+}{ }^{+}$lymphocytes' PD- 1 expression and ACAPA level.

g. Correlation between $\mathrm{CD} 4^{+}$lymphocytes' PD-1 expression and RF level.

h. Correlation between $\mathrm{CD}^{+}{ }^{+}$lymphocytes' PD-1 expression and DAS28 score.

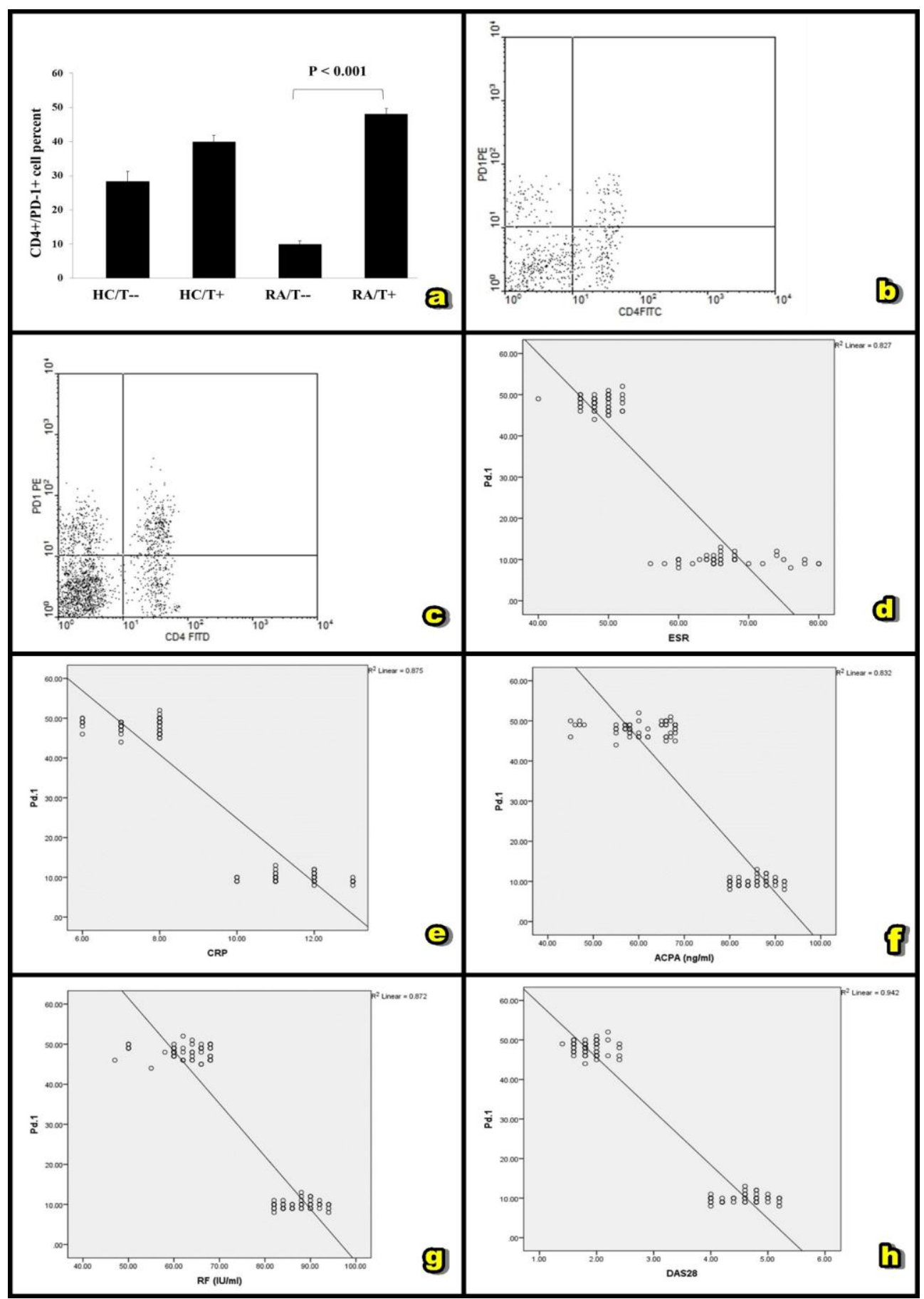


Influence of $T$. gondii on PD-1 expression on both $\mathrm{CD}^{+}$and $\mathrm{CD}^{+}$lymphocytes was recorded in many previous studies. Bhadra et al., (2011 and 2012) and Moretto et al., (2017) reported an increased lymphocytic expression of PD-1 in chronic toxoplasmosis due to lymphocytic exhaustion and this PD-1 increase was responsible for reactivation of latent infections. Xiao et al., (2018) also documented the important role of PD-1 in toxoplasmosis reactivation. Its blockade was found to preserve potent immune response that could reduce brain cysts of $T$. gondii. Hwang et al., (2018) reported that increased expression of inhibitory molecules starts once infection turns into the chronic stage and gradually increases. The significant variation in PD-1 expression of lymphocytes of RA/T and $\mathrm{RA} / \mathrm{T}^{+}$patients can explain the delayed onset of RA manifestations. Results of Belkhir et al., (2017) supports ours. They recorded RA incidence in $60 \%$ of patients who received anti-PD1 antibodies as a part of cancer immunotherapy. Manifestations appeared in patients who were totally negative for RA. The relation between decreased severity markers and increased PD1 in $\mathrm{RA} / \mathrm{T}^{+}$patients is supported by findings of Menzies et al., (2017) who reported flaring of RA and other autoimmune diseases in patients who received anti-PD-1 immunotherapy and had a previous autoimmune disease.

In conclusion, $T$. gondii infection enhanced the $\mathrm{CD}^{+}$lymphocytic expression of the immune-suppressive molecule, PD-1. It caused the delayed onset of RA and decreased its severity markers. So, better disease prognosis is expected in presence of $T$. gondii infection.

\section{References}

Aletaha, D., Neogi, T., Silman, A.J., Funovits, J., Felson, D.T., Bingham, C.O., Birnbaum, N.S., Burmester, G.R.,
Bykerk, V.P., Cohen, M.D., Combe, B., Costenbader, K.H., Dougados, M., Emery, P., Ferraccioli, G., Hazes, J.M., Hobbs, K., Huizinga, T.W., Kavanaugh, A., Kay, J., Kvien, T.K., Laing, T., Mease, P., Ménard, H.A., Moreland, L.W., Naden, R.L., Pincus, T., Smolen, J.S., Stanislawska-Biernat, E., Symmons. D., Tak, P.P., Upchurch, K.S., Vencovský, J., Wolfe, F., and Hawker, G. 2010. Rheumatoid arthritis classification criteria: an American College of Rheumatology/European League Against Rheumatism collaborative initiative. Arthritis Rheum. 62(9): 2569- 81. https://doi.org/10.1002/art.27584.

Anderson, J. K., Zimmerman, L., Caplan, L., and Michaud, K. 2011. Measures of rheumatoid arthritis disease activity: patient (PtGA) and provider (PrGA) global assessment of disease activity, Disease Activity Score (DAS) and Disease Activity Score with 28-Joint Counts (DAS28), Simplified Disease Activity Index (SDAI), Clinical Disease Activity Index (CDAI), Patient Activity Score (PAS) and Patient Activity Score-II (PASII), Routine Assessment of Patient Index Data (RAPID), Rheumatoid Arthritis Disease Activity Index (RADAI) and Rheumatoid Arthritis Disease Activity. Arthritis care res. 63(11): 14-36.

Belkhir, R., Burel, S.L., Dunogeant, L., Marabelle, A., Hollebecque, A., Besse, B., Leary, A., Voisin, A.L., Pontoizeau, C., Coutte, L., Pertuiset, E., Mouterde, G., Fain, O., Lambotte, O., and Mariette, X. 2017. Rheumatoid arthritis and polymyalgia rheumatica occurring after immune checkpoint inhibitor treatment. Ann. Rheum. Dis. 76(10): 1747-1750. https://doi.org/10.1136/ annrheumdis-2017-211216.

Bhadra, R., Gigley, J.P. and Khan, I.A. 2011. The CD8 T-cell road to immunotherapy of toxoplasmosis. Immunotherapy. 3(6): 
789-801. https://doi.org/10.2217/imt.11. 68

Bhadra, R., Gigley, J.P., and Khan, I.A. 2012. D-1-mediated attrition of polyfunctional memory $\mathrm{CD} 8+\mathrm{T}$ cells in chronic toxoplasma infection. J. Infect. Dis. 206(1): 125-34. https://doi.org/10.1093/ infdis/jis304.

Ceeraz, S., Hall, C., Choy, E.H., Spencer, J. and Corrigall, V.M. 2013. Defective $\mathrm{CD} 8+\mathrm{CD} 28+$ regulatory $\mathrm{T}$ cell suppressor function in rheumatoid arthritis is restored by tumour necrosis factor inhibitor therapy. Clin. Exp. Immunol. 174(1): 18-26. https://doi.org/10.1111/cei.12161.

Deb, A., Dwibedi, N., LeMasters, T., Hornsby, J.A., Wei, W., and Sambamoorthi, U. 2018. Burden of Depression among Working-Age Adults with Rheumatoid Arthritis. Arthritis. 2018: 8463632. https://doi.org/10.1155/2018/8463632.

Doran, M. F., Crowson, C. S., Pond, G. R., O'Fallon, W. M., and Gabriel, S. E. 2002. Predictors of infection in rheumatoid arthritis. Arthritis \& Rheumatism. 46(9): 2294-2300.

El-Henawy, A.A., Hafez, E.A.R., Nabih, N., Shalaby, N.M. and Mashaly, M. 2017. Anti-Toxoplasma antibodies in Egyptian rheumatoid arthritis patients. Rheumatol. Int. 37(5):785-790. https://doi.org/10.1007/s00296-0173703-8.

El-Sayed, N.M., Ismail, K.A., Badawy, A.F., Elhasanein, K.F. 2015. In vivo effect of anti-TNF agent (etanercept) in reactivation of latent toxoplasmosis. $\mathrm{J}$. Parasit. Dis. 40(4): 1459-1465. https://doi.org/10.1007/s12639-0150712-y.

El-Sayed, N.M., Kishik, S.M., and Fawzy, R.M. 2016. The current status of Toxoplasma gondii infection among Egyptian rheumatoid arthritis patients. Asian Pac. J. Trop. Dis. 6(10): 797-801. https://doi.org/10.1016/S2222-1808(16) 61133-7.
Englbrecht, M., Kruckow, M., Araujo, E., Rech, J., and Schett, G. 2013. The interaction of physical function and emotional wellbeing in rheumatoid arthritis--what is the impact on disease activity and coping? Semin. Arthritis. Rheum. 42(5): 482-91. https://doi.org/10.1016/j. semarthrit.2012.09.003.

Fischer, S., Agmon-Levin, N., Shapira, Y., Porat Katz, B.S., Graell, E., Cervera, R., Stojanovich, L., Gómez Puerta, J.A., Sanmartí, R., and Shoenfeld, Y. 2013. Toxoplasma gondii: bystander or cofactor in rheumatoid arthritis. Immunol. Res. 56(2-3): 287-92. https://doi.org/10.1007/s12026-0138402-2.

Gilmour, D., and Sykes, A. J. 1951. Westergren and Wintrobe methods of estimating ESR compared. Br. Med J. 22; 2(4746): 1496-7.

Greisen, S.R., Yan, Y., Hansen, A.S., Ven $\varnothing$, M.T., Nyengaard, J.R., Moestrup, S. K., Hvid, M., Freeman, G.J., Kjems, J., and Deleuran, B. 2017. Extracellular vesicles transfer the receptor Programmed Death-1 in Rheumatoid Arthritis. Front. Immunol. 8:851. https://doi.org/10.3389/fimmu.2017.008 51.

Gulácsi, L., Brodszky, V., Baji, P., Kim, H., Kim, S.Y., Cho, Y.Y., and Péntek, M. 2015. Biosimilars for the management of rheumatoid arthritis: economic considerations. Expert. Rev. Clin. Immunol. $11 \quad$ (1): 43-52. https://doi.org/10.1586/1744666X.2015. 1090313.

Halonen, S.K., and Weiss, L.M. 2013. Toxoplasmosis. Handb. Clin. Neurol. 114:125-45.

https://doi.org/10.1016/B978-0-44453490-3.00008-X.

Hosseininejad, Z., Sharif, M., Sarvi, S., Amouei, A., Hosseini, S.A., NayeriChegeni, T., Anvari, D., Saberi, R., Gohardehi, S., Mizani, A., Sadeghi, M., and Daryani, A. 2018. Toxoplasmosis seroprevalence in 
rheumatoid arthritis patients: A systematic review and meta-analysis. PLoSNegl. Trop. Dis. 12(6): e0006545. https://doi.org/10.1371/journal.pntd.000 6545

Hwang, Y.S., Shin, J.H., Yang, J.P., Jung, B.K., Lee, S.H., and Shin, E.H. 2018.Characteristics of infection immunity regulated by Toxoplasma gondii to maintain chronic infection in the brain. Front. Immunol. 5 (9):158. https://doi.org/10.3389/fimmu.2018.001 58.

Lassoued, S., Zabraniecki, L., Marin, F., and Billey, T. 2007. Toxoplasmic chorioretinitis and antitumor necrosis factor treatment in rheumatoid arthritis. Semin. Arthritis Rheum. 36(4):262-3. https://doi.org/10.1016/j.semarthrit.2006 .08 .004

Li, S., Liao, W., Chen, M., Shan, S., Song, Y., Zhang, S., Song, H., and Yuan, Z. 2014. Expression of programmed death-1 (PD-1) on CD4+ and CD8+ T cells in rheumatoid arthritis. Inflammation. 37(1):116-21. https://doi.org/10.1007/s10753-0139718-8

Listing, J., Gerhold, K., and Zink, A. 2013. The risk of infections associated with rheumatoid arthritis, with its comorbidity and treatment. Rheumatology (Oxford). 52(1):53-61. https://doi.org/10.1093/rheumatology/ke s305

Liu, C., Jiang, J., Gao, L., Hu, X., Wang, F., Shen, Y., Yu, G., Zhao, Z., and Zhang X. 2014. A Promoter Region Polymorphism in PDCD-1 Gene Is Associated with Risk of Rheumatoid Arthritis in the Han Chinese Population of Southeastern China. Int. J. Genomics. 2014: $247637 . \quad$ https://doi.org/10. $1155 / 2014 / 247637$

McInnes, I.B. and Schett, G. 2017. Pathogenetic insights from the treatment of rheumatoid arthritis. Lancet. 389 (10086): 2328-2337. https://doi.org/10. 1016/S0140-6736(17)31472-1
Menzies, A.M., Johnson, D.B., Ramanujam, S., Atkinson, V.G., Wong, A.N.M., Park, J.J., McQuade, J.L., Shoushtari, A.N., Tsai, K. K., Eroglu, Z., Klein, O., Hassel, J.C., Sosman, J.A., Guminski, A., Sullivan, R.J., Ribas, A., Carlino, M.S. Davies, M.A., Sandhu, S.K., and Long, G.V. 2017. Anti-PD-1 therapy in patients with advanced melanoma and preexisting autoimmune disorders or major toxicity with ipilimumab. Ann. Oncol. 28(2):368-376. https://doi.org/ 10.1093/annonc/mdw443.

Moretto, M.M., Hwang, S., and Khan, I.A. 2017. Downregulated IL-21 Response and T Follicular Helper Cell Exhaustion Correlate with Compromised CD8 T Cell Immunity during Chronic Toxoplasmosis. Front. Immunol. 8: $1436 . \quad$ https://doi.org/ 10.3389/fimmu.2017.01436

Prokunina, L., Padyukov, L., Bennet, A., de Faire, U., Wiman, B., Prince, J., Alfredsson, L., Klareskog, L., and Alarcón-Riquelme, M. 2004. Association of the PD-1.3A allele of the PDCD1 gene in patients with rheumatoid arthritis negative for rheumatoid factor and the shared epitope. Arthritis Rheum. 50(6):1770-3. https://doi.org/10.1002/art.20280

Raptopoulou, A.P., Bertsias, G., Makrygiannakis, D., Verginis, P., Kritikos, I., Tzardi, M., Klareskog, L., Catrina, A.I., Sidiropoulos, P., and Boumpas, D.T. The programmed death 1/programmed death ligand 1 inhibitory pathway is up-regulated in rheumatoid synovium and regulates peripheral $\mathrm{T}$ cell responses in human and murine arthritis. Arthritis Rheum. 2010 Jul;62(7):1870-80. https://doi.org/10.1002/art.27500

Sandigursky, S., Silverman, G.J., and Mor, A. 2017. Targeting the programmed cell death-1 pathway in rheumatoid arthritis. Autoimmun. Rev. 16(8): 767- 773. https://doi.org/10.1016/ j.autrev.2017.05.025 
Shapira, Y., Agmon-Levin, N., Selmi, C., Petríková, J., Barzilai, O., Ram, M., Bizzaro, N., Valentini, G., MatucciCerinic, M., Anaya, J.M., Katz, B.S., and Shoenfeld, Y. 2012. Prevalence of anti-Toxoplasma antibodies in patients with autoimmune diseases. J Autoimmun. $\quad 39(1-2)$ : $112-6$. https://doi.org/10.1016/j.jaut.2012.01.00 1

Sharaf EL-Deen, S.A., Brakat, R.M., and Mohamed, A.S. 2018. Soluble Tachyzoite Antigen Immunization Can Protect Mice from Experimental Autoimmune Encephalomyelitis Via Induction of programmed death-1. J. Am. Sci. 14(3): 1-13. https://doi.org/10.7537/marsjas140318.0 1

Taylor, P.C., Moore, A., Vasilescu, R., Alvir, J., and Tarallo M. 2016. A structured literature review of the burden of illness and unmet needs in patients with rheumatoid arthritis: a current perspective. Rheumatol. Int. 36(5):68595. https://doi.org/10.1007/s00296-0153415-x

Tian, A.L., Gu, Y.L., Zhou, N., Cong, W., Li, G.X., Elsheikha, H.M., and Zhu, X.Q. 2017. Seroprevalence of Toxoplasma gondii infection in arthritis patients in eastern China. Infect. Dis. Poverty. 6(1): 153 . 1186/s40249-017-0367-2

https://doi.org/10.

Washino, T., Moroda, M., Iwakura, Y., and Aosai, F. 2012. Toxoplasma gondii infection inhibits Th17-mediated spontaneous development of arthritis in interleukin-1 receptor antagonistdeficient mice. Infect. Immun. 80(4): 1437- 44. https://doi.org/10.1128/ IAI.05680-11

World Health Organization Chronic rheumatic conditions. http//:www.who. int/chp/topics/rheumatic/en/ Accessed 19 nov 2018

Xiao, J., Li, Y., Yolken, R.H., and Viscidi, R.P. 2018. PD-1 immune checkpoint blockade promotes brain leukocyte infiltration and diminishes cyst burden in a mouse model of Toxoplasma infection. J. Neuroimmunol. 319: 5562. https://doi.org/10.1016/j. jneuroim.2018.03.013

Young, J.D., McGwire, B.S. 2005. Infliximab and reactivation of cerebral toxoplasmosis. N Engl. J. Med. 353(14): 1530-1; discussion 1530-1. https://doi.org/10.1056/NEJMc051556

\section{How to cite this article:}

Sharaf El-Deen, S.A., R.M. Brakat, R.M. El-Kholy, D.S. Saif, Soliman, S.A. 2019. Toxoplasma gondii Infection Delays the Onset and Decreases the Severity of Rheumatoid Arthritis in a Programmed Death-1 Mediated Mechanism. Int.J.Curr.Microbiol.App.Sci. 8(05): 80-90. doi: https://doi.org/10.20546/ijcmas.2019.805.011 